\title{
A comparative evaluation of serological assays for lepromatous leprosy
}

\author{
J MWATHA $\ddagger$, C MORENO, U SENGUPTA, $\dagger$ \\ S SINHA $† \&$ J IVANYI* \\ *MRC Tuberculosis and Related Infections Unit, Hammersmith \\ Hospital, Ducane Road, London W12 OHS; †Central JALMA \\ Institute for Leprosy, Taj Ganj, Agra-282001, India; and $\ddagger$ Alupe \\ Leprosy and Skin Diseases Research Centre, PO Box 3, Busia, \\ Kenya
}

\section{Accepted for publication 15 April 1988}

\begin{abstract}
Summary A comparative antibody analysis of sera from 26 patients with lepromatous leprosy showed consistently high titres to the phenolic glycolipid I disaccharide and to the ML04 epitope of the $35 \mathrm{kD}$ protein antigen of Mycobacterium leprae. Antibody titres of these two specificities were positively correlated $(p<0.01)$ and both declined after chemotherapy, although this trend was apparent earlier after the onset of therapy for the anti-35kD antibody response. Two healthy subjects (out of 18 tested) from the leprosy endemic area had pronounced anti-PGL-1 but no demonstrable anti-35kD antigen activities. In contrast with the above results, antibody levels to lipoarabinomannan were much lower and with great individual variation between the LL patients. Finally, antibody levels to the $M$. leprae-specific IIIE9 epitope (peptide 422-436) of the $65 \mathrm{kD}$ protein antigen were not demonstrable in the majority of LL patients.
\end{abstract}

\section{Introduction}

Serological studies in leprosy have been pursued for the past 80 years ${ }^{1}$ with interest in diagnosis, classification within the spectrum of disease, monitoring of chemotherapy, prognosis of subclinical inf ection ${ }^{2}$ and response to vaccination. ${ }^{3}$ Recent progress in the molecular definition of Mycobacterium leprae-specific, antigenic determinants provided a new impetus to these studies. The phenolic glycolipid I (PGL-1) and its terminal disaccharide have been used in a solid-phase binding enzymelinked assay, ${ }^{4-6}$ whereas a competition test has been applied using monoclonal antibodies (MAB) to the $35 \mathrm{kD}$ antigen and other protein or polysaccharide antigens, ${ }^{7-12}$

These assays confirmed results from previous studies which showed that serum antibody levels are profoundly increased in multibacillary (lepromatous) but not in paucibacillary (tuberculoid) leprosy. The relative immunodominance of the respective antigens has not as yet been fully evaluated. The purpose of this paper has been to compare antibody levels to distinct epitopes in individual patients with lepromatous leprosy. 


\section{Materials and Methods}

SERA

Thirty patients, attending the clinic of the JALMA Institute for Leprosy (Agra, India) were classified as lepromatous leprosy (LL) according to the Ridley-Jopling scale. The 18 control sera were from healthy subjects living in the Agra region. Sera were collected from patients before and at various times after chemotherapy which was given in accordance with WHO recommendations. ${ }^{13}$

\section{ANTI 35 KD PROTEIN, ML04-COMPETITION ASSAY}

Microtitre plates (Immulon, M129B Dynatech) were coated with $50 \mu \mathrm{g} / \mathrm{ml}$ (25 $\mu \mathrm{l} /$ well) M. leprae soluble extract (MLSE) for $20 \mathrm{hr}$ at $4{ }^{\circ} \mathrm{C}$. Af ter washing 3 times with phosphate buffered saline (PBS) the plates were blocked with $3 \%$ bovine serum albumin (BSA) in PBS for $1 \mathrm{hr}$ at $20^{\circ} \mathrm{C}$ and serum samples, serially diluted $(100-51200)$ in $3 \%$ BSA- $0.05 \%$ Tween -20 were added to wells. After 30 min incubation at $37^{\circ} \mathrm{C}$ in a humidified chamber, peroxide-labelled ML04 MAB $(25 \mu \mathrm{l} /$ well $)$ in BSA-Tween was added and incubated for $1 \mathrm{hr}$ at $37^{\circ} \mathrm{C}$. Plates were washed and incubated with $3,3^{\prime}, 5^{\prime} 5^{\prime}$ tetramethyl benzidine (TMB) $-\mathrm{H}_{2} \mathrm{O}_{2}$ substrate $(100 \mu \mathrm{l} /$ well, of a fresh solution containing 50 $\mu \mathrm{g} / \mathrm{ml} \mathrm{TMB}$ and $0.006 \% \mathrm{H}_{2} \mathrm{O}_{2}$ in $0.08 \mathrm{M} \mathrm{Na}$ Citrate $\mathrm{pH} \mathrm{5.0)}$ for $30 \mathrm{~min}$ at $20^{\circ} \mathrm{C}$. The reaction was stopped with $50 \mu \mathrm{l} /$ well of $0.5 \mathrm{M} \mathrm{H}_{2} \mathrm{SO}_{4}$ and the optical density read at $450 \mathrm{~nm}$ in a titertek multiscan reader. Antibody titres are expressed as reciprocal serum dilutions giving 50\% inhibition of ML04 binding to MLSE coated wells $\left(\mathrm{ID}_{50}\right)$.

\section{ANTI-LIPOARABINOMANNAN (LAM) ML34-COMPETITION ASSAY}

This test was performed with MAB ML34 which binds to an epitope expressed on (LAM). ${ }^{15,16}$ The competition assay was done essentially as described in the previous paragraph, but using ${ }^{125} \mathrm{I}-$ labelled ML34 as in the original technique. ${ }^{17}$

\section{PHENOLIC GLYCOLIPID BINDING ASSAY}

Microtitre plates were coated with $5 \mu \mathrm{g} / \mathrm{ml}$ phenolic glycolipid I disaccharide (PGDS) (3,6Dimethyl- $\beta$-D-Glucosyl (1-4) 2,3-Dimethyl- $\alpha$-L-Rhamnosyl) conjugated to BSA (from R Gigg) in PBS $\left(50 \mu \mathrm{g} /\right.$ well) for $20 \mathrm{hr}$ at $4{ }^{\circ} \mathrm{C}$, washed with PBS and blocked with $3 \% \mathrm{BSA}$ for $1 \mathrm{hr}$ at $37^{\circ} \mathrm{C}$ in a humid chamber. Serial doubling dilutions (100-51200) of test sera in $1 \%$ BSA Tween $(50 \mu \mathrm{l} /$ well) were added to PGDS-coated or uncoated plates and incubated for $2 \mathrm{hr}$ at $37^{\circ} \mathrm{C}$. Plates were washed with Tween/PBS, then incubated with $50 \mu \mathrm{l} /$ well of $1: 1000$ diluted peroxidase coupled goat antihuman IgM (Sigma Chem. Co. UK) for $1 \mathrm{hr}$ at $37^{\circ} \mathrm{C}$. After washes with Tween/PBS, substrate was added and the reaction read as described above. Relative binding values were calculated over the range of serum dilutions with OD values corrected for binding to the uncoated plate, using a positive reference serum as $100 \%$. Antibody titres were expressed as reciprocal serum dilutions giving $15 \%$ binding $\left(\mathrm{ABT}_{15}\right)$.

\section{ANTI-65kD ANTIGEN TESTS}

Microtitre plates were coated overnight at $4^{\circ} \mathrm{C}$ with $50 \mu \mathrm{l} /$ well of the $M$. leprae-specific IIIE9 peptide ${ }^{18}$ dissolved in $0.1 \mathrm{M} \mathrm{Na}$ bicarbonate at $0.1 \mu \mathrm{g} / \mathrm{ml}$ concentration. Plates were washed with PBS and blocked for $1 \mathrm{hr}$ at room temperature with BSA/Tween. After incubation with sera for $2 \mathrm{hr}$ and washing with PBS, plates were incubated for $1 \mathrm{hr}$ with $1 / 1000$ dilution of peroxidase con jugated rabbit anti-human IgG (Sigma Chemical Co) in BSA/Tween, washed, and developed as described above. The IIIE9 MAB was used as the positive control. 
Additional tests were performed with radiolabelled IVD8 antibody ${ }^{12}$ using the competition assay as described before. ${ }^{17}$

\section{ST ATISTICAL ANALYSIS}

Correlations betweeen antibody titres of the various specificities and for antibody titres related to years of chemotherapy were analysed using correlation coefficients.

Table 1. Antibody levels in patients with lepromatous leprosy

\begin{tabular}{|c|c|c|c|c|c|}
\hline \multirow[b]{2}{*}{$\begin{array}{l}\text { Sample } \\
\text { no. }\end{array}$} & \multirow[b]{2}{*}{$\begin{array}{l}\text { Years of } \\
\text { therapy: }\end{array}$} & \multirow[b]{2}{*}{ BI* } & \multicolumn{3}{|c|}{ Antibodies $\dagger$ to: } \\
\hline & & & $\begin{array}{c}35 \mathrm{kD} \\
\mathrm{ID}_{50}\end{array}$ & $\begin{array}{l}\text { PGDS } \\
\mathrm{ABT}_{15}\end{array}$ & $\begin{array}{l}\text { LAM } \\
\text { ID }_{50}\end{array}$ \\
\hline \multicolumn{6}{|l|}{ Patients } \\
\hline 1 & 0 & $3 \cdot 7$ & 8440 & 4380 & 71 \\
\hline 2 & 0 & 4 & 6860 & $>5120$ & 87 \\
\hline 3 & 0 & 5 & 8440 & 1698 & 31 \\
\hline 4 & 0 & 4 & 7350 & 3308 & 14 \\
\hline 5 & 0 & 4 & 8440 & 15219 & 577 \\
\hline 6 & 0 & 5 & 2110 & 1537 & 172 \\
\hline 7 & 0 & 4 & 690 & 12775 & 69 \\
\hline 8 & 0 & NA & 8440 & 6182 & 268 \\
\hline 9 & 0 & $4 \cdot 5$ & 6400 & 5385 & 102 \\
\hline 10 & 0 & NA & 1710 & 4217 & 291 \\
\hline 11 & 3 & 0 & 1260 & $<100$ & 13 \\
\hline 12 & 3 & 0 & 5200 & 221 & 68 \\
\hline 13 & 3 & 2 & 320 & 1131 & 219 \\
\hline 14 & 3 & NA & 1130 & 3591 & $>625$ \\
\hline 15 & 3 & 3 & 350 & 1440 & 68 \\
\hline 16 & 4 & 3 & 12800 & 16781 & 125 \\
\hline 17 & 5 & 5 & 3200 & 18243 & 268 \\
\hline 18 & 6 & 0 & 1130 & 2588 & 115 \\
\hline 19 & 7 & 0 & 800 & 282 & 25 \\
\hline 20 & 8 & 0 & 120 & 2983 & 87 \\
\hline 21 & 10 & 1 & 920 & 572 & 74 \\
\hline 22 & 10 & 0 & $<100$ & 976 & 20 \\
\hline 23 & 12 & 0 & 300 & 146 & 20 \\
\hline 24 & 12 & 0 & $<100$ & 428 & 21 \\
\hline 25 & 12 & 0 & 400 & 100 & 17 \\
\hline 26 & 15 & NA & $<100$ & 5761 & 16 \\
\hline \multicolumn{6}{|l|}{ Controls } \\
\hline $1-16$ & & & $<100$ & $<100$ & $10-50$ \\
\hline 17 & & & $<100$ & 1479 & 26 \\
\hline 18 & & & $<100$ & 1130 & 25 \\
\hline
\end{tabular}

* Bacteriological index. NA, not available.

$\dagger$ The values represent reciprocal dilutions (titres) of test sera giving $50 \%$ inhibition $\left(\right.$ ID $\left._{50}\right)$ of binding of monoclonal antibody ML04 (35kD protein) and ML34 (LAM) or giving $15 \%$ binding to PGDS coated micotitre plates. 


\section{Results and Discussion}

Sera from untreated patients showed consistently high antibody levels in the PGDS binding and the anti-35kD (ML04) competition assays (Table 1). The performance of the ML04 competition test using peroxidase-labelled ML04 monoclonal antibody showed considerably higher serum titres than in previous assays which employed a radiolabelled ML04.,8

Unlike the uniformly raised anti-PGDS and anti-35kD protein antibodies, we observed considerable variation between individual LL patients in their anti-LAM antibody response, represented by the ML34-competition test. The individual variations could not be related to the bacteriological index. These results related only to one epitope (ML34) of LAM and the immunogenicity of epitopes detected by other MABs (ML02) ${ }^{15}$ (L9) ${ }^{10}$ was not evaluated.

In view of the cross-reactivity of the ML34 epitope of LAM with several mycobacteria, ${ }^{16}$ it is not surprising to find antibody levels in healthy controls which consequently limits the usef ulness for diagnosis of leprosy. High titres of antibodies against phenolic glycolipid I were found in 2 out of 18 control sera which were negative in the ML04 competition test. This result is in agreement with previous reports of 'false' positive reactions to PGL-1 in 5\% of control sera..$^{5,12}$

Correlation between these tests was examined with the sera from patients prior to therapy and those with up to 5 years of therapy. PGDS vs ML34 and PGDS vs ML04 showed positive correlation at the $p<0.02$ and $p<0.01$ levels respectively whilst no significant correlation was found between ML04 vs ML34.

All three tests showed a statistically significant correlation between decrease of titres and length of chemotherapy. The ML04-competition test showed by far the best correlation $(p<0.001)$ and may therefore be the most suitable for monitoring the response of patients to chemotherapy.

Marginal levels of binding activity to the IIIE9 peptide of the 65KD protein were demonstrable in sera of 2 patients only. Competition experiments using radiolabelled IVD8 antibody, whose epitope is also contained on the IIIE9 peptide, showed similarly marginal activity in sera with very high anti-35kD and PGDS antibody levels (results not shown). Therefore, our results suggest that the $M$. leprae specific epitope of the $65 \mathrm{kD}$ antigen is poorly immunogenic in patients with lepromatous leprosy.

In conclusion, we found that essentially all patients with LL produce high levels of antibodies towards PGL-1 and $35 \mathrm{kD}$ protein antigen. This strong immunodominance and the speciesspecificity of both epitopes is particularly favourable for further serodiagnostic and seroepidemiological evaluation. This is apparent in view of the fact that sera from LL patients do not contain significant antibody titres to two other $M$. leprae specific epitopes defined by the ML06/ML10 MABs on the $12 \mathrm{kD}$ antigen ${ }^{7}$ and by the IIIE9/IVD8 MABs on the $65 \mathrm{kD}$ antigen. Of the other MAB-defined $M$. leprae specific epitopes, it appears that only half of the LL patients react with the $18 \mathrm{kD}$ antigen ${ }^{10}$ whilst the response to the $28 \mathrm{kD}$ antigen ${ }^{19}$ has not yet been evaluated. Technically, the availability of chemically synthesized PGDS is favourable for assay standardization although variable levels of non-specific IgM binding to the solid phase interfere with the analysis of sera at low dilutions. On the other hand, the competition assay is less prone to non-specific factors and therefore possibly more reliable to detect low antibody levels.

\section{Acknowledgments}

We thank V Aber for statistical evaluation, R Gigg for the supply of PGL-disaccharide, P Kim and $\mathrm{R}$ Young for the IIIE9 peptide, T Buchanan for the IVD8 monoclonal antibody, J Duncan for peroxidase conjugation of antibodies and D Young for advice. 


\section{References}

1 Melsom R. Serodiagnosis of Leprosy: The Past, the Present and Some Prospects for the Future. Int J Lepr, 1983; 51: 235 .

2 Ashworth M, Sinha S, Patil SA, Ramu G, Sengupta U. The detection of subclinical leprosy using a monoclonal antibody based radioimmunoassay. Lepr Rev, 1986: 57: 237.

${ }^{3}$ Gill HK, Mustafa AS, Ivanyi J, Harboe M, Godal T. Humoral immune responses to M. leprae in human volunteers vaccinated with killed, armadillo-derived M. leprae. Lepr Rev, 1986; 57: 293.

4 Young DB, Buchanan TM. A serological test for leprosy with a glycolipid specific for M ycobacterium leprae. Science, 1983: 221: 1057.

${ }^{5}$ Cho S-N, Fujiwara T, Hunter SW, Rea TH, Gilber RH, Brennan PJ. Use of an artificial antigen containing the 3,6-di-o-methyl-B-D-glucopyranonyl epitope for the serodiagnosis of leprosy. J Inf Diseases, 1984; 150: 311.

${ }^{6}$ Brett SJ, Payne SN, Gigg J, Burgess P, Gigg R. Use of synthetic glycoconjugates containing the Mycobacterium leprae specific and immunodominant epitope of phenolic glycolipid I in the serology of leprosy. Clin exp Imm, 1986; 64: 476.

7 Sinha S, Sengupta U, Ramu G, Ivanyi J. A serological test for leprosy based on competitive inhibition of monoclonal antibody binding to the MY2a determinant of Mycobacterium leprae. Trans Roy Soc Trop Med Hyg, 1983; 77: 869.

8 Sinha, S, Sengupta U, Ramu G, Ivanyi J. Serological survey of leprosy and control subjects by a monoclonal antibody-based immunoassay. Int J Lepr 1985; 55: 33.

9 Klatser PR, De Wit YL, Kolk HJ. An ELISA-inhibition test using monoclonal antibody for the serology of leprosy. Clin exp Imm. 1985; 62: 468.

${ }^{10}$ Britton WJ, Hellquist L, Basten A, Raison RL. Mycobacterium leprae antigens involved in human immune responses. I. Identification of four antigens by monoclonal antibodies. J Imm, 1985; 135: 4171.

11 Reitan LJ, Closs O, Harboe M. Characterization of the immune response to a n epitope on Mycobacterium leprae Antigen 7 defined by a monoclonal antibody. Scand J Immunol, 1985; 22: 711.

12 Levis WR, Meeker HC, Schuller-Levis GB, Gillis TP, Marino LJ, Zabriskie J. Serodiagnosis of Leprosy: Relationships between Antibodies to Mycobacterium leprae Phenolic Glycolipid I and Protein Antigens. 1986; $24: 917$.

13 WHO Study Group. Chemotherapy of leprosy for control programmes. Technical Report Series No 675. WHO: Geneva, 1982.

${ }^{14}$ Duncan RJS, Weston, PD, Wrigglesworth R. A new reagent which may be used to introduce sulfhydryl groups into proteins, and its use in the preparation of conjugates for immunoassay. Anal Biochem, 1983; 132: 68 .

15 Hunter SW, Gaylord H, Brennan PJ. Structure and antigenicity of the phosphorylated lipopolysaccharide antigens from leprosy and tubercle bacilli. J Biol Chem, 1986; 261: 12345.

${ }^{16}$ Ivanyi J, Sinha S, Aston R, Cussell D, Keen M, Sengupta U. Definition of species specific and cross-reactive antigenic determinants of Mycobacterium leprae using monoclonal antibodies. Clin exp Imm, 1983: 52: 528.

${ }^{17}$ Hewitt J, Coates ARM, Mitchison DA, Ivanyi J. The use of monoclonal antibodies without purification of antigen in the serodiagnosis of tuberculosis. J Immunol Meth, 1982; 55: 205.

18 Mehra V, Sweetser D, Young RA. Efficient mapping of protein antigenic determinants. Proc Natl Acad Sci (USA), 1986; 83: 7013.

19 Young DB, Fohn MJ, Khanolkar SR, Buchanan TM. Monoclonal antibodies to a 28,000 mol. wt protein antigen of Mycobacterium leprae. Clin exp Imm 1985; 60, 546. 


\section{LEPROSY CONTROL AND FIELD WORK}

\section{Prometheus-PHC (Primary Health Care)}

Dr Manuel Quimper, Instituto de Medicina Tropical, 'Alexander von Homboldt', A.P. 5045, Lima, Peru, South America, has developed a project for the use of microcomputers to improve primary health care services in Peru. The descriptive leaflet summarizing this interesting initiative includes the following:

Prometheus-PHC: A computerized, integrated health information system:

Designed to improve the quality of primary health care services . . . and other medical services in Peru and other countries.

Information technology which works first at the community level . . where the real needs of the people are and secondly at the level of direct supervision.

Computer-based expert assistance for health promotors ... and an automated system for planning and supervision at health centres and area hospitals.

Appropriate high level technology: Powerful microcomputers which work with batteries, have no moving parts and are recharged by inexpensive solar panels (less than $\$ 20$ each) made in Peru.

An 'intelligent' system: an exact, continuously up-dated community census, which monitors and records all health services activities, automatically schedules future primary health care visits, monitors the growth and development of all community children, records all immunization and precisely targets future needs, automatically manages inventories of medicines and supplies, and provides expert assistance for the diagnosis and treatment of: diarrhoea, respiratory infections, malnutrition, high risk pregnancy, fever, trauma, emergency. Rapid error-free transmission of information between computers of all types at different levels of the Health System.

Avoiding loss of data through redundant storage of information.

The Prometheus-PHC prototype being used, at this moment in the central jungle region of Peru:

In 10 health posts along the Rio Pichis, the Prometheus-PHC pilot project has shown that:

Prometheus-PHC is reliable, well received, and can be easily used by local health promotors in their native communities.

Local promotors can be trained in the use of the system in less than 1 week even those who have never seen a typewriter before.

Dr Quimper has supplied the following additional technical information:

The equipment about which you asked me in your letter of 29 March is a real Microcomputer, an item which belongs to the so called 'Lap top personal computers' with a RAM (Random Access Memory) of $275 \mathrm{Kbytes,}$ powered by a rechargeable 9 Volt battery.

The computer, a Hewlett-Packard 110 model, had no mobile parts and was shown to be a robust, and reliable piece of equipment (at least for the first 2 years).

We developed in the country the solar energy unit for the recharging of the batteries, using discarded (broken) materials brought from a factory in the USA, and manufactured the panels with our own craftsmen. They cost less than US $\$ 5$ each. The sof tware was designed by us and the programming was in Basic language.

At the beginning of the project we ran into some difficulties because of the small storing capacity of the batteries. However, introducing a 12 Volt standard acid battery (car type), as an additional accumulator, we improved the capacity of power storing and went on without any further problems.

At the end of the project, some of the computers presented problems related to the lif espan of the internal batteries, which diminished the amount of charge they could hold. Again, that was solved by replacing the batteries with new ones, a task performed locally, though it required a special type of screwdriver.

(The approach, on the evidence so far, seems of potential value for the collection of data in the field and it is apparently workable by local health staff. As many people in South America and elsewhere, are already familiar with keyboards, visual display units and computers, this initiative warrants further attention. Editor.)

\section{United Nations Association International Service; Brazil}

We are indebted to Jane Carter, General Secretary of UNAIS, 3 Whitehall Court, London SW1A 2EL, for keeping us informed about a series of volunteers from the UK who have been recruited to work in the Manaus area of Brazil, under the supervision of Prof essor Sinesio Talhari. Qualified nurses are being sent out to help supervise the multiple drug therapy programme in the Amazonas; they do this from small health centres or clinics in 4 designated centres of population, at varying distances from the capital of Manaus. Experience has already shown that this improves training of local staff and adequate follow-up of patients. This project, operating under difficult conditions, well away from the more developed centres in Brazil, is supported by CAFOD and LEPRA and is likely to be on-going over the next 5 years at least. 